Universidade Tecnológica Federal do Paraná - UTFPR

Campus Ponta Grossa - Paraná - Brasil

ISSN 1808-0448 / v. 04, n. 01: p. 116-130, 2008

D.O.I.: $10.3895 / \mathrm{S} 1808-04482008000100008$

\author{
Revista Gestão Industrial
}

\title{
UM MANUAL DE GESTÃO AMBIENTAL PARA AS INDÚSTRIAS GRÁFICAS: CONHECIMENTO SOCIALMENTE PRODUZIDO
}

\section{MANUAL OF ENVIRONMENTAL MANAGEMENT FOR GRAPHIC INDUSTRY: SOCIAL KNOWLEDGE PRODUCTION}

\author{
Iracema Pinto de Souza ${ }^{1}$; Maclovia Corrêa da Silva ${ }^{2}$ \\ ${ }^{1}$ Universidade Tecnológica do Paraná - UTFPR - Curitiba, Brasil - iracema@infante.com.br \\ ${ }^{2}$ Universidade Tecnológica Federal do Paraná - UTFPR —Curitiba, Brasil - maclovia@unicamp.br e \\ macloviasilva@utfpr.edu.br
}

\begin{abstract}
Resumo
A idéia de que a implantação da Gestão Ambiental como modelagem para resolver problemas relacionados ao meio ambiente requer altos investimentos, gera custos, e é um privilégio de grandes empresas, pode ser um posicionamento de especialistas que deixam de inserir em suas avaliações as questões inovativas da capacidade humana e dos conhecimentos socialmente produzidos. Esse trabalho tem por objetivo apresentar um modo de uso do conhecimento tácito para inovações, valorizando as práticas ambientais sugeridas por pessoas que estão diariamente envolvidas com o processo produtivo de empresas gráficas, aliado à intenção de reduzir custos de produção, de minimizar os impactos ambientais e de oferecer qualidade ambiental para as empresas com baixos custos. A criação do "Manual Técnico-Ambiental" foi o resultado de esforços para resolver questões ambientais relativas a quatro importantes sistemas de impressão: Ofsete, Flexografia, Serigrafia e Tipografia. Sua finalidade visa orientar empresas gráficas quanto às metodologias de prevenção à poluição, identificação de resíduos em seus processos produtivos, bem como oportunidades de melhoria. O processo de conscientização e orientação teve início em 2001, com a publicação do "Guia Prático de Orientação para Questões Ambientais da Indústria Gráfica”, uma realização dos órgãos de classe nacional. Em 2003, o "Guia Técnico-Ambiental da Indústria Gráfica" foi desenvolvido com parceria de sindicatos e federações: Sindicato das Indústrias Gráficas do Estado de São Paulo; Federação das Indústrias do Estado de São Paulo; Central da Indústria do Estado de São Paulo; Secretaria de Meio Ambiente; e Companhia de Tecnologia de Saneamento Ambiental/Secretaria de Meio Ambiente de São Paulo.
\end{abstract}

Palavras-chave: gestão ambiental; socialização do conhecimento; indústria gráfica.

\section{Introdução}

O objetivo desse estudo é mostrar a importância de se organizar diretrizes de ações ambientais na área empresarial provindas de práticas inovativas construídas no cotidiano da produção gráfica. A 
idéia da criação do "Manual Técnico-Ambiental" que trata das questões ambientais relativas a quatro importantes sistemas de impressão - Ofsete, Flexografia, Serigrafia e Tipografia - nasceu dentro das necessidades crescentes de se aperfeiçoar a extração de recursos naturais e a deposição de rejeitos no meio ambiente. Sua finalidade premente é fornecer orientações às empresas gráficas quanto às metodologias de prevenção à poluição, identificação de resíduos em seus processos produtivos, bem como oportunidades de melhoria. Conforme estatísticas realizadas pelo Instituto Brasileiro de Geografia e Estatística, o lançamento de novos produtos no mercado interno ainda é a prática inovativa mais aplicada pelos empresários brasileiros. O sistema de cálculo não contempla uma articulação com as estatísticas ambientais. A diretoria de pesquisa, e outras diretorias, que mantêm relações com a sociedade civil e organizações governamentais deveriam, segundo Mueller (2004, p. 319) estar trabalhando na "constituição de um sistema integrado de estatísticas ambientais [...] que necessita enfatizar as inter-relações entre a economia e o meio ambiente".

O capítulo III da lei federal $n^{\circ} 11.196$, regulamentado pelo Decreto Federal $n^{0} 5.798$, trata dos incentivos fiscais para a inovação tecnológica nas empresas brasileiras. No texto do documento a inovação tecnológica está definida como "a concepção de novo produto ou processo de fabricação, bem como a agregação de novas funcionalidades ou características ao produto ou processo que implique melhorias incrementais e efetivo ganho de qualidade ou produtividade", para o mercado da oferta e da demanda. Dentre as atividades inovativas, o governo brasileiro propõe incentivos nas seguintes áreas: pesquisa básica dirigida, pesquisa aplicada, desenvolvimento experimental de novos produtos, processos sistemas e serviços, tecnologia industrial básica e serviços de apoio técnico.

Importante é o entendimento que para gerar inovações na área de gestão ambiental, seja baseada na pesquisa científica, ou na experiência cotidiana de produção, é possível aumentar os ganhos em qualidade e produtividade com baixos investimentos. Todavia, conforme estudos efetuados por Freeman (citado por LEMOS, 2000, p. 161),

\footnotetext{
$\mathrm{Na}$ emergência de um paradigma, quando novas tecnologias surgem com mais intensidade, parece ser mais evidente que as fontes baseadas em conhecimentos científicos possuem papel fundamental para a introdução de inovações de cunho mais radical. Já em sua maturidade, quando as tecnologias já estão dominadas, as fontes relacionadas a conhecimentos adquiridos com a experiência da empresa se tornam mais e mais importantes para que as firmas estejam aptas a gerar aperfeiçoamentos e obter inovações incrementais.
}

A autora explica que os conhecimentos tácitos são gerados no processo inovativo, e são de natureza cumulativa e especificamente localizada, facilitando o desenvolvimento de capacitações 
tecnológicas endógenas. Mas, poder-se-ia perguntar: que conhecimento seria este? Será que pode ser aprendido em sala de aula? Seria o que está contido nos manuais de produtos ou serviços? Ocorre que certos conhecimentos somente são apropriados pela experiência e, raramente por meio de treinamentos ou de cursos ministrados pelo sistema de educação tradicional. Por ser difícil expressá-lo verbalmente, ou na modalidade escrita, e de ser percebido apenas no momento que procedimentos ou atitudes se fazem necessário, esse conhecimento fica classificado como tácito, distinguindo-se assim do explícito que é passível de registro, comprovação, e pode ser encontrado em livros ou em documentação de processos de atendimento ou produção.

Bastos (1997) diz que educação, trabalho, ciência, e tecnologia são segmentos diferenciados, todavia todos eles fazem parte do processo de produção e acumulação de conhecimento teórico-prático necessários ao ser social. No entanto,

\footnotetext{
...é necessária uma aproximação estreita entre o entendimento dos avanços científicos e tecnológicos e o saber dos "aplicadores" de tecnologias, sejam eles discentes, docentes, pesquisadores ou quaisquer outros trabalhadores, a fim de informá-los sobre seu papel na transformação técnica da produção e do trabalho, bem como capacitá-los para discernir entre técnicas que contribuam para o aumento ou a diminuição das desigualdades sociais (p.26, 27).
}

Acredita-se que as empresas podem conquistar diferenciais competitivos a partir de práticas inovativas de transferência de conhecimentos tácitos. A transferência do conhecimento tácito é um modo de colocar em questão os processos de ensino-aprendizagem descontextualizados, ultrapassando os limites de abrangência dos treinamentos organizacionais, na medida em que englobam a identificação, conversão, transferência e disseminação de um conhecimento que muitas vezes é de difícil explicitação.

Os saltos em produtividade e a flexibilidade nas empresas demandam trabalhadores qualificados. Faria (1997, 0. 172), ao estudar as conseqüências da automação sobre o processo de trabalho, explica que desde os anos de 1900, quando os trabalhadores contestaram a introdução das máquinas de tecelagem, destruindo-as, está marcada a competitividade entre o trabalho realizado por um ser humano e por uma máquina: "até hoje, os debates quanto à questão da qualificação admite opiniões favoráveis (“a tecnologia é qualificadora”) e desfavoráveis (“a tecnologia desqualifica o trabalhador").

Ou seja, o trabalhador, dentro dos perfis de qualificação que se modificam constantemente, pode se tornar um simples executor de tarefas desmotivado: “...a característica de maior peso é o fato desse trabalho não exigir do trabalhador o seu "saber profissional", o "saber fazer" reduzindo-o [...] a 
um executor de operações mecânicas, monótonas e inconsciente" (ibid, p. 173). O uso do saber profissional dos empregados é um modo de valorização das iniciativas que pode vir justamente de boas práticas ambientais, sugeridas por pessoas que estão diariamente envolvidas no processo produtivo das empresas, aliado à intenção de reduzir custos de produção, e desejando agir de forma a minimizar os impactos ambientais.

Vale lembrar que se os trabalhadores desempenharem suas funções fora de uma sistemática de produção, que exija parâmetros ambientais de qualidade, a empresa poderia estar perdendo produtividade e aumentando seus custos. Por vezes, com poucos investimentos, e com os conhecimentos tácitos, é possível ajustar os procedimentos de um sistema de produção: “o aprendiz não se detém à execução de ofícios, pois ele é intérprete das tecnologias para transformá-las a partir do uso e da manipulação" (BASTOS, 1998, p. 35). Quando os trabalhadores transformam suas rotinas, em consonância com os processos inovativos, novos conhecimentos geram comportamentos diferenciados. Zeny (1997, p. 110) explica que as soluções de problemas ambientais para empresas podem ser simples, como o desvio de água limpa para córregos próximos de instalações, o reaproveitamento de água limpa para outros usos dentro das fábricas, porém em termos de poluição do ar,

Nem sempre se tem uma tecnologia alternativa para se dar um destino adequado a este resíduo. Hoje em dia, Curitiba conta com a Central da Casa de Resíduos Industriais, mas o custo chega, às vezes, a R $\$ 240,00$ por tonelada, o qual é elevadíssimo para se dar algo que poderia ser, ou melhor utilizado dentro da própria fábrica, ou um subproduto, ou ainda matéria-prima para outra indústria, dentro desta visão de se dar uso-agregar valor aos resíduos.

O historiador Keith Thomas (1989), ao estudar as relações do homem com o mundo natural explica como o conhecimento tácito foi sendo deixado de lado para dar lugar ao conhecimento científico. Na sua pesquisa documental, ele observou que o trabalhador agrícola inglês era um conhecedor do seu ambiente de trabalho e de termos para classificar os animais e as plantas. Este conhecimento popular foi sendo deixado de lado à medida que os cientistas desenvolveram investigações mais sistemáticas: "Dessa forma, a agricultura tradicional revelou-se eivada de ignorância." (Thomas, 1989, p. 88). As visões, erudita e popular do mundo da natureza, separam-se pela noção mais forte e mais fraca de racionalidade.

Bastos (1998) diz que a evolução das técnicas veio acompanhada das necessidades de formação do homem. À medida que isso se consolida, crescem os impactos entre o trabalho manual e o intelectual. A racionalidade predomina e articulam-se meios para se chegar a fins que podem trazer resultados inesperados. Duas categorias definem as mudanças tecnológicas: "a inovação - que consiste 
na distribuição de novos produtos e novos procedimentos e a racionalização - que conduz à produção de bens e serviços com melhor rendimento e mais economia" (1998, p.43).

\section{Gestão ambiental}

É o sistema que inclui a estrutura organizacional, atividades de planejamento, responsabilidade, práticas, procedimentos, processos e recursos para desenvolver, implementar, atingir, analisar criticamente e manter as políticas traçadas. É a forma pela qual a organização se mobiliza, interna e externamente para a conquista da qualidade ambiental desejada. Ela consiste em um conjunto de medidas que visam ter controle sobre o impacto ambiental de uma atividade, portanto, começa a ser encarada como um assunto estratégico dentro das organizações e isso tem se tornado um fator importante de competitividade.

A gestão ambiental empresarial está essencialmente voltada para as organizações, ou seja, companhias, corporações, empresas ou instituições. Ela pode ser entendida como uma série de regras que incluem as políticas, os programas e as práticas administrativas e operacionais que levam em conta a proteção do meio ambiente, mediante a eliminação ou minimização de impactos ambientais adversos decorrentes do planejamento, implantação, operação, ampliação ou desativação de empreendimentos ou atividades, incluindo-se também a análise do ciclo de vida de um produto ou da empresa.

É o sistema que inclui a estrutura organizacional, atividades de planejamento, responsabilidade, práticas, procedimentos, processos e recursos para desenvolver, implementar, atingir, analisar criticamente e manter a política ambiental. É a forma pela qual a organização se mobiliza, interna e externamente para a conquista da qualidade ambiental desejada. Ela consiste em um conjunto de medidas que visam ter controle sobre o impacto ambiental de uma atividade, portanto, começa a ser encarada como um assunto estratégico dentro das organizações e isso tem se tornado um fator importante de competitividade.

A gestão ambiental empresarial está essencialmente voltada para as organizações, ou seja, companhias, corporações, empresas ou instituições. Ela pode ser entendida como uma série de regras que incluem as políticas, os programas e as práticas administrativas e operacionais que levam em conta a proteção do meio ambiente, mediante a eliminação ou minimização de impactos ambientais adversos decorrentes do planejamento, implantação, operação, ampliação ou desativação de empreendimentos ou atividades, incluindo-se também a análise do ciclo de vida de um produto ou da empresa. 


\section{Benefícios auferidos pela gestão ambiental}

Pode-se auferir aos procedimentos de gestão ambiental empresarial a relação custo-benefício e verificar ações que provocam economias de custo como o consumo de água, energia e outros insumos do processo produtivo; aumento da contribuição marginal de "produtos verdes" que podem ser colocados no mercado com preços diferenciados; e criação de linhas de novos produtos que sejam menos poluidores para consumidores especiais.

As empresas que adotarem uma postura de favorecer a diminuição dos impactos causados pela extração e deposição de rejeitos da natureza assumem o compromisso de respeitar a imagem institucional, as relações de trabalho, de socializar o conhecimento, os acordos com o governo, comunidades e grupos ambientalistas. Por outro lado, as portas para o mercado externo estarão abertas ampliando as possibilidades de aumentar a produtividade, e de se adquarem aos padrões internacionais de qualidade (CAGNIN, 1999).

A Gestão Ambiental inicia-se através do diagnóstico de cada processo de produção que deve ser feito por pessoas que tenham condições de, minuciosamente, descrever cada etapa de elaboração do

produto. É muito interessante, ao ser feito o diagnóstico, que as pessoas envolvidas no processo de produção participem para detectar os problemas que vão surgindo à medida que o trabalho vai acontecendo, permitindo que, ao final, o levantamento e conclusão do diagnóstico apontem soluções economicamente viáveis e possíveis de serem realizadas, possibilitando a real implantação da gestão ambiental.

Vale dizer que no momento da elaboração deste suposto diagnóstico, feito com a inclusão das pessoas da produção, a empresa tem outros ganhos, que são gerados pela motivação e pelo contágio atraindo os membros da empresa que não quiseram inserir-se na análise, podendo atingir desde membros da diretoria até os que atuam no chão de fábrica. Assim, será viabilizado também um dos objetivos da gestão ambiental que é trazer para dentro da empresa um novo olhar sobre a economia de recursos do meio ambiente em termos globais.

A empresa de posse do diagnóstico feito, em cada processo, tem a possibilidade de quantificar a água utilizada, o consumo de energia, a emissão de gazes decorrentes da utilização de químicos ou outro tipo de produto, de mensurar a quantidade e tipo de resíduos que produz e como é feito esse descarte. Ela estará mais atenta para elaborar critérios de compra de matéria-prima, terá condições de perceber o quanto é desperdiçado durante o processo produtivo e como a empresa é impactante para o meio ambiente, bem como, o grau de repercussão desse comportamento na comunidade a qual está inserida. De posse dessas informações, trabalhadores da produção, que participaram na elaboração 
desse diagnóstico, passam a definir estratégias de melhoria no processo produtivo com o comprometimento e envolvimento de todos os colaboradores da empresa, gerando redução de custos devido à adequação da empresa na busca da eficiência competitiva, conseqüentemente ganho financeiro (lucros).

\section{0 segmento industrial gráfico}

O segmento industrial gráfico brasileiro é um exemplo dessa prática de gestão ambiental citada acima. A criação do "Manual Técnico-Ambiental da Indústria Gráfica" é o resultado do esforço conjunto de órgãos e entidades empresariais e governamentais na busca de resultados comuns para a solução dos impactos ambientais causados pelo setor produtivo. Ele está focado na questão operacional e apresenta detalhes dos processos de controle ambiental para quatro dos principais processos de impressão: Offset, Flexografica, Serigrafia e Tipografia. O seu conteúdo traz uma introdução sobre sistemas de impressão e aborda técnicas de prevenção à poluição, programas e conceitos necessários para essa finalidade, identificação de entradas e saídas nos sistemas de impressão, oportunidades de melhorias, legislação ambiental e glossário técnico.

Trata-se de um trabalho permanente do setor na busca de uma indústria gráfica ambientalmente correta. Essa conscientização e orientação tiveram início em 2001, com a publicação do "Guia Prático de Orientação para Questões Ambientais da Indústria Gráfica", uma realização do SINDIGRAF-SP (Sindicato da Indústria Gráfica de São Paulo), ABIGRAF (Associação Brasileira da Indústria Gráfica) e ABTG (Associação Brasileira de Tecnologia Gráfica). Em 2003, o “Guia Técnico-Ambiental da Indústria Gráfica" foi desenvolvido numa parceria entre SINDIGRAF-SP (Sindicato da Indústria Gráfica de São Paulo), FIESP (Federação da Indústria do Estado de São Paulo) - CIESP (Centro das Indústrias do Estado de São Paulo), SMA (Secretaria do Meio Ambiente de São Paulo) e CETESB (Companhia de Tecnologia de Saneamento Ambiental). No mesmo ano (2003) foi desenvolvida uma parceria entre os Sindicatos das Indústrias Gráficas dos Estados do Rio Grande do Sul, São Paulo e Paraná, com o apoio das respectivas Abigrafs (Associação Brasileira das Indústrias Gráficas) Regionais para a elaboração do "Manual Técnico-Ambiental da Indústria Gráfica”, que servirá de orientação para toda a indústria gráfica brasileira.

A indústria gráfica é muito diversificada, pois atende a todos os setores da economia, incluindo serviços públicos, serviços financeiros, publicitários, editoriais, prestadores de serviços e a indústria de manufatura como um todo. Para atenders demandas tão diferenciadas, a indústria possui diferentes 
processos de produção e presta serviços para campos específicos. A indústria gráfica brasileira é responsável por aproximadamente 200 mil empregos diretos, com investimentos da ordem de US\$ 6 bilhões em máquinas, equipamentos, novas tecnologias e infra-estrutura acumulados no período de 1990 a 2000.

Os principais produtos da indústria gráfica incluem: Jornais. Rótulos/Etiquetas, Periódicos/Revistas, Formulários, Livros, Envelopes, Mapas, Embalagens de Papel Cartão, CartõesPostais, Embalagens Flexíveis, Calendários, Transfers, Impressos de Segurança, Materiais de Sinalização, Materiais Publicitários (promocionais), e outros. O total de estabelecimentos gráficos no Brasil é de 14.326 (RAIS/98 E CAGED 99/00). Embora o valor da indústria seja significativo no volume total de produtos e serviços da Nação, aproximadamente $87 \%$ das empresas gráficas empregam menos de 20 pessoas e servem mercados locais e regionais.

Quanto à questão ambiental, os princípios de respeito à natureza ainda precisam ser inseridos no contexto empresarial gráfico como objeto de avaliação e análise. Há carência de informações e dados estatísticos que possam dimensionar e orientar as estratégias de combate à degradação do meio ambiente e redução de custo de produção através da eficiência competitiva.

\section{Os sistemas gráficos de impressão e as agressões à natureza}

Os sistemas de impressão analisados nesse artigo são os intitulados: ofsete, flexografia, serigrafia e tipografia. Esses processos se diferenciam pelo método de transferência de imagem e tipo de matriz utilizada. O sistema ofsete é um processo de impressão indireto no qual a imagem é entintada na chapa, sendo primeiramente transferida para uma blanqueta e depois para o substrato. A chapa é tratada fotoquimicamente a fim de produzir áreas de grafismo e de contragrafismo, recepctivas à tinta e à água, respectivamente. Apresenta três características que o distinguem dos demais: as áreas de grafismo e contragrafismo encontram-se no mesmo plano; a impressão é indireta, ou seja, a imagem é transferida da chapa para uma blanqueta e desta para o substrato; é o único processo que envolve água. A impressão offset pode ser plana, usada para a impressão de livros, periódicos, pôsteres, promocionais, brochuras, cartões, rótulos e embalagens, ou rotativa, comumente usada para a impressão de jornais, livros, tablóides, revistas, catálogos, periódicos, promocionais.

O processo de impressão que usa formas flexíveis de borracha ou polímero com as áreas de grafismo em alto-relevo, imprimindo diretamente sobre o suporte, utilizando tintas fluídas e voláteis de secagem rápida ou tinta UV chama-se flexografia. Caracteriza-se pela impressão de embalagens, etiquetas, rótulos, produtos de sacarias, listas telefônicas, jornais, sacolas, e embalagens corrugadas. 
Outro processo de impressão é a serigrafia, que utiliza uma moldura e uma tela de tecido, plástico ou metal, permeável à tinta nas áreas de grafismo e impermeabilizada nas áreas de contragrafismo, sobre a qual a tinta é espalhada e forçada por uma lâmina de borracha através das malhas abertas, para atingir o suporte. É um processo versátil que permite estampar sobre diferentes tipos de materiais e superfícies irregulares ou curvas, incluindo papel, vidro, plástico,madeira, e metal. Os principais produtos são impressos comerciais, pôsteres, banners, estamparia têxtil, etiquetas adesivas, painéis industriais, e convites, dentre outros. A tipografia emprega a forma gravada em altorelevo, transferindo a tinta das áreas elevadas diretamente para o substrato. Uso mais comum da impressão tipográfica; formulários, bilhetes, marcas e impressos comerciais em geral.

No caso da prevenção da poluição, os objetivos ambientais nacionais e os interesses socioeconômicos das indústrias coincidem. Existem fortes incentivos sociais e econômicos para a redução, tanto da toxicidade como do volume geral dos despejos gerados. Para adequar o processo produtivo da indústria gráfica, gerador de resíduos em grande escala, aos procedimentos de gestão ambiental é necessário elaborar um programa de redução de resíduos com o compromisso de cumprir os objetivos, e de organizar equipes para acompanhar constantemente o andamento do planejamento. Caso contrário, o programa estará fadado ao insucesso. Portanto, é importante que o compromisso parta da alta administração e que seja dado às equipes suporte para as ações. Responsáveis definidos conduzirão esse trabalho.

A prevenção da poluição é a redução máxima viável de todas as espécies de resíduos gerados nos locais de produção. Envolve a aplicação das melhores práticas de gerenciamento, uso correto de recursos por meio da redução na fonte, eficiência no uso de energia, reaproveitamento dos materiais que entram nos sistema - "input" - durante a produção e consumo reduzido de água. Dois métodos gerais de redução na fonte que são úteis num programa de prevenção da poluição são: mudanças no produto e mudanças no processo. Essas práticas podem reduzir a quantidade e/ou a toxicidade dos despejos da produção e dos produtos finais durante seu ciclo de vida e no momento de sua disposição final.

Há benefícios e oportunidades para melhorias num programa de prevenção da poluição, tanto no campo ambiental como no econômico. Esses benefícios podem ser agrupados em quatro categorias principais: obediência à legislação e aos regulamentos; custos operacionais diretos e indiretos; riscos ambientais e processos legais de cunho ambiental; e imagem pública e interna da corporação. 


\section{A criação do Manual Técnico-Ambiental}

As empresas que foram objetos de estudo para a elaboração do Manual Técnico-Ambiental foram analisadas a partir das idéias que são citadas a seguir:

1. Relacionar todos os processos e dados da empresa;

2. Priorizar e selecionar objetivos de avaliação;

3. Montar o time de avaliação;

4. Revisar todos os dados e inspecionar os locais geradores de resíduos;

5. Gerar opções.

Para facilitar a utilização deste Manual Técnico-Ambiental, as empresas devem aplicar os seus Programas de Controle de Saúde Ocupacional - PCMSO e Programas de Prevenção de Riscos Ambientais - PPRA, que contém dados técnicos necessários para a aplicação correta das oportunidades de melhorias mencionadas no manual técnico, bem como conhecer conceitos necessários para a aplicação desses programas.

O PCMSO - NR 7 - estabelece a obrigatoriedade da elaboração e implementação, por parte de todos os empregados e instituições que admitam trabalhadores como empregados, do Programa de Controle Médico de Saúde Ocupacional - PCMSO, com o objetivo de promoção e preservação da saúde do conjunto dos seus trabalhadores, e o PPRA - NR 9 - estabelece a obrigatoriedade da elaboração e implementação, por parte de todos os empregadores e instituições que admitam trabalhadores, do Programa de Prevenção de Riscos Ambientais - PPRA, visando à prevenção da saúde e à integridade dos trabalhadores.

Segundo a norma NBR 10.004, de 31 de maio de 2004, válida a partir de 30.11.04, da Associação Brasileira de Normas Técnicas (ABNT), os resíduos sólidos devem ser classificados para o correto gerenciamento dos mesmos dentro da empresa. Os resíduos são classificados em:

a) Resíduos Classe I - Perigososos (em função de suas propriedades físicas, químicas ou infectocontagiosas);

b) Resíduos Classe II - Não-Perigosos: (em função da biodegradabilidade, combustibilidade ou solubilidade em água);

c) Resíduos Classe II A - Não-Inertes;

d) Resíduos Classe II B - Inertes.

$\mathrm{Na}$ aplicabilidade do manual é importante que as empresas tenham conhecimento desses conceitos, os quais ajudam na compreensão, mensuração e classificação de substâncias tóxicas, efluentes líquidos e emissões atmosféricas. Todos os processos de impressão gráficos estão divididos 
em três etapas: pré-impressão impressão; pós-impressão. As três etapas de cada processo gráfico poluem de alguma forma a água, o solo e o ar. Descreve-se a seguir como o processo produtivo da indústria gráfica interage com o meio ambiente e acaba interferindo no equilibro dos sistemas ecológicos.

Na pré-impressão ocorre poluição das águas, do solo e do ar. Na fase da impressão, novamente acontece a poluição das águas e a contaminação do solo. Na pós-impressão, mais uma vez as águas, o solo e o ar são impactados. A prevenção desse tipo de poluição seria a redução máxima viável de todas as espécies de resíduos gerados nos locais de produção. No Manual Técnico-Ambiental, sugere-se a aplicação de melhores práticas de gerenciamento, o uso correto dos recursos por meio da redução na fonte (mudanças no produto e mudanças no processo), a eficiência no uso de energia o reaproveitamento dos materiais que entram no sistema - input - durante a produção, e o consumo reduzido de água.

O planejamento para reduzir um impacto ambiental também interfere na vida útil do produto, nas práticas operacionais, na seleção de materiais no input, e na mudança de tecnologias. Com isso, os custos e os riscos sobre os processos diminuem, e a competitividade aumenta. Há várias outras maneiras de prevenção da poluição nas operações de impressoras gráficas. Ao adotar boas práticas, o manual recomenda a adoção de um processo de melhoria contínua.

A seguir, estão descritas práticas consideradas pelo manual como eficientes para tratar os resíduos gráficos:

a) Gerenciamento de Resíduos: Reprojetar, reduzir e reutilizar - maior prioridade - reciclar, recuperar energia e dispor em aterro - menor prioridade;

b) Redução do Consumo de substâncias tóxicas: - o ideal é utilizar solventes que possam ser reciclado ou identificar produtos que os substituam e sejam eficientes e menos poluentes;

c) Redução de resíduos sólidos: - a implementação da coleta seletiva é vital para a correta segregação dos resíduos sólidos;

d) Toalhas reutilizáveis, estopas ou trapos: - utilizar toalhas de pano, que podem ser lavadas e reutilizadas. Evitar a utilização de toalhas de papel, trapos ou estopas, que deverão ser gerenciados como resíduos especiais (classe I);

e) Manejo dos suportes de impressão: - as materiais utilizados com suporte na impressão, ainda que não sejam materiais perigosos, têm seu custo de aquisição, geram um volume de aparas, sobras e descarte de material impresso de tal monta que os tornam prioritários no planejamento da melhoria ambiental;

f) Matrizes de impressão: - utilizar gravação a laser sobre borracha no processo flexográfico; 
g) Manejo de tinta: - a empresa deve fazer um gerenciamento no setor de tintas, para diminuição do consumo de tinta, por meio da utilização de balança eletrônica para confecção da mesma na quantidade necessária e armazenamento da fórmula utilizada, para posterior reprodução da mesma cor sem desperdício de tinta;

h) Manejo do solvente: - identificar e rastrear todo o consumo de solventes para melhor gerenciamento do mesmo;

i) Limpeza de impressoras: - implementação sistemática para redução de setup e manutenção preventiva;

j) Redução no consumo de energia: - reduzir o consumo de energia em curto e longo prazo;

k) Redução de ruídos e vibração: - através da colocação dos compressores de ar das máquinas impressoras em locais adequados, manutenção preventiva dos equipamentos;

1) Redução da geração de efluentes líquidos: - criação de estações de tratamento de efluentes;

m) Redução da geração de emissões atmosféricas.

\section{Conclusão}

Considerando que não somente as grandes empresas estão à frente na adoção de boas práticas de gestão ambiental, através de sua capacidade financeira, que possibilita o acesso à tecnologia, mas também as pequenas e médias empresas estão preocupadas com a questão ambiental, o Manual Técnico-Ambiental da Indústria Gráfica oferece alternativas para todas as organizações que necessitem seguir a tendência de mercado de interagir com os ciclos produtivos e com os ciclos da natureza. Há hoje uma classe de consumidores que compra produtos de empresas que sejam responsáveis ambientalmente e que usem de forma sustentável os recursos naturais.

A criação do Manual Técnico-Ambiental da Indústria Gráfica é um exemplo de iniciativa voltada para as pequenas e médias empresas do setor que oportuniza as organizações, independente de seu porte ou potencial poluidor, orientação de como proceder para otimizar seus processos produtivos, possibilitando a redução de custos operacionais, o aumento do lucro e agindo de forma responsável em relação ao meio ambiente.

As gráficas utilizam como matéria-prima o papel e tem como insumos tinta, chapa de alumínio, químicos, verniz, fotolito entre outros. Através da ABIGRAF (Associação das Indústrias Gráficas Nacional) foi possível a elaboração do manual ambiental para cada segmento industrial gráfico (tipográfico, ofsete, flexografia e serigrafia). Pelo diagnóstico realizado em algumas empresas dos diferentes segmentos, pode-se pensar em estabelecer um critério básico para que as indústrias gráficas, 
principalmente de pequeno e médio porte, para dar início ao gerenciamento dos resíduos produzidos, com trabalho contínuo e integrado.

É importante destacar que esse manual auxilia a gráfica no levantamento do diagnóstico e na implantação de boas práticas ambientais, sendo, portanto, aplicável a qualquer porte de empresa não necessitando de grandes investimentos e nem de tecnologia para viabilizá-lo. O trabalho que o segmento gráfico vem fazendo no Brasil para reduzir o impacto ambiental da atividade, já é real nas cidades de Curitiba, Porto Alegre e São Paulo. Elas adquirem produtos químicos ambientalmente corretos em substituição aos considerados poluentes, apesar do preço. Sendo mais caros, eles apresentam a vantagem de ganho na quantidade necessária pelo seu grau de concentração, compensando os ganhos e perdas. Isso representa para as empresas economia, ganho de produtividade e benefícios para o meio ambiente.

É recomendável que a partir do Manual Técnico-Ambiental de sistematização de procedimentos na indústria gráfica, as empresas do setor façam contatos com suas concorrentes e conheçam como é possível fazer parcerias que reduzam o impacto ambiental. A implantação pode ser de forma gradual, porém precisa ser permanentemente reciclada. O estabelecimento de metas progressivas é um demonstrativo de boa vontade e interesse pela preservação do planeta, por parte do empreendedor, e de sua equipe de trabalho, com quem socializará esses conhecimentos.

\begin{abstract}
The idea that the environmental management as a model to solve problems, related to environment, demands high investments, produces profits, and it is a privilege for big enterprises, can be a specialist position that leaves inserting in his evaluations the human abilities to innovate and to produce social knowledge. This paper has the mean to present a way to use the tacit knowledge to innovate, giving value to environmental practices suggested by the people that work daily in the productive process of graphic industries, allied to the intention to reduce production costs, minimize environmental impacts and to offer environmental quality for the enterprises with low costs. The creation of "Environmental Technician Manual" was the result of efforts to solve environmental questions related to four important systems of impression: Offset printing, plastic printing, cloth printing, graphic and Printer's. It finality aims to orientate the graphic enterprises in their methodologies to prevent pollution, identify residues in the productive process, as well to give improvement opportunities. The awareness and orientation process began in 2001, with the publication of the "Practical Guide of orientation for environmental questions in the Graphic Industries", a realization of the national private institutions. In 2003, the "Technical Environmental Guide for Graphic Industries" was developed with partnership of trade unions and federations. "Sindicato das Indústrias Gráficas do Estado de São Paulo; Federação das Indústrias do Estado de São Paulo; Central da Indústria do Estado de São Paulo; Secretaria de Meio Ambiente; e Companhia de Tecnologia de Saneamento Ambiental/Secretaria de Meio Ambiente de São Paulo".
\end{abstract}

Key-words: Environmental management; knowledge socialization; graphic industry. 


\section{Referências}

BASTOS, J.A. O Programa de Pós-Graduação em Tecnologia do Centro Federal de Educação Tecnológica Federal do Paraná - CEFET-PR: história e perspectivas. Revista Educação e Tecnologia. Curitiba, CEFETs - PR/MG/RJ, ano 1, n. 1 abr. 1997, p. 11-52.

BASTOS, J.A. A educação tecnológica: conceitos, características e perspectivas. Revista Tecnologia e Interação. Curitiba, Programa de Pós-Graduação em Tecnologia/CEFET-PR, 1998. 174p.

CAGNIN (1999). North, K. Environmental business management. Genebra: ILO, 1992.

FARIA, J. Trabalho, tecnologia e sofrimento: as dimensões desprezadas do mundo do trabalho. Revista Educação e Tecnologia. Curitiba, CEFETs - PR/MG/RJ, ano 4, n. 6 mai. 2003, p. 169-190.

LEMOS, C. Inovação na era do conhecimento. Revista Parcerias Estratégicas. Rio de Janeiro: n.8, mai 2000, p. 157-179. MANUAL TÉCNICO AMBIENTAL DA INDÚSTRIA GRÁFICA. Curitiba/PR. 2006.

MUELLER, C. Contas nacionais e o meio ambiente: reflexões em torno de uma abordagem para o Brasil. In: ROMEIRO, A. R. Avaliação e contabilização de impactos ambientais. São Paulo, Imprensa Oficial, 2004.

THOMAS, K. O homem e o mundo natural: mudanças de atitude em relação às plantas e aos animais (1500-1800). São Paulo: Companhia Das Letras, 1989.

ZENY, A. Gestão ambiental: práticas e princípios. Revista Educação e Tecnologia. Curitiba, CEFETs - PR/MG/RJ, ano 1, n. 1 abr. 1997, p. 109-115.

\section{Dados dos autores}

Nome completo: Iracema Pinto de Souza

Filiação institucional: empresária do setor gráfico e membro do grupo de estudos "Tecnologia e Meio Ambiente" do Programa de Pós-Graduação em Tecnologia da Universidade Tecnológica do Paraná -

\section{UTFPR}

Departamento: Programa de Pós-Graduação em Tecnologia

Função ou cargo ocupado: membro do grupo de estudos "Tecnologia e Meio Ambiente"

Endereço completo para correspondência: Rua Piauí, 2010 - Vila Guaíra - CEP - 80630-300 Curitiba

-Paraná-Brasil

Telefones para contato: 41 3333-3166 - 41 9926-1282

e-mail - iracema@infante.com.br

Nome completo: Maclovia Corrêa da Silva

Filiação institucional- professora do Programa de Pós-Graduação em Tecnologia da Universidade Tecnológica Federal do Paraná - UTFPR — Curitiba, Paraná, Brasil

Departamento: Programa de Pós-Graduação em Tecnologia

Função ou cargo ocupado: professora 
Endereço completo para correspondência: Avenida Sete de Setembro, 3165 - CEP - 80230-901 Curitiba -Paraná -Brasil

Telefones para contato: $413310-4659$ - $413242-3364$

e-mail-․maclovia@unicamp.bre macloviasilva@utfpr.edu.br

Recebido para publicação em: 04/02/2008

Aceito para publicação em: 28/02/2008 